\title{
A Large Intracardiac Clear Cell Sarcoma Metastasis
}

\author{
Cowles Charles E ${ }^{1 *}$, Thakar Dilip ${ }^{1}$ and Thakar Sudip ${ }^{2}$ \\ ${ }^{1}$ Anesthesiology and Perioperative Medicine, University of Texas MD Anderson Cancer Center, USA \\ ${ }^{2}$ Anesthesiology and Perioperative Medicine, Baylor College of Medicine, USA
}

Submission: February 02, 2018; Published: February 21, 2018

*Corresponding author: Cowles Charles E, Anesthesiology and Perioperative Medicine, University of Texas MD Anderson Cancer Center, USA, Email: cowlesmd@gmail.com

\section{Introduction}

Intercardiac metastasis of melanoma, melanoma variants and soft tissue sarcomas are more common than many clinicians realize and noted to be a fairly common autopsy finding in patients with metastatic melanoma [1]. Our case presented is one of extensive cardiac tumor involvement, which was not fully appreciated by transthoracic echocardiography (TTE) and was found to be quite extensive when a transesophageal echocardiography (TEE) was performed. Reviews of the patient's records illustrate the progression of her intercardiac disease despite aggressive treatment regimens.

\section{Case}

A 37-year-old Asian female presented to the operating room for a palliative resection of hemorrhagic metastases of the right parietal and the left frontal areas of the brain. Her initial diagnosis of soft tissue clear cell sarcoma was 3.5 years prior with a current stage of IV M1c. The patient was treated with radiation therapy, interferon, and autologous cytokine induced killer cells immunotherapy. Two years following this treatment regimen, a follow-up positron emission and computerized axial tomography (PET-CT) imaging indicated uptake in the left ventricle, pancreas, and small lesions in the lungs. At this time the cardiac lesions were evaluated via TTE and a $2.0 \times 1.7 \mathrm{~cm}$ left ventricular mass adherent to the lateral wall was noted.

Seven months later (now 3 years past initial diagnosis) she was admitted from the emergency center for sepsis, adrenal insufficiency, and hypotension. A TTE performed at that time showed an LVEF of 55-50\% and a small pericardial effusion and the left ventricular mass had increased to 3.3 by $1.7 \mathrm{~cm}$. Within two months she was admitted for tachycardia and was found to be in atrial fibrillation with intermittent ventricular tachycardia. A repeat TTE was performed and showed a new right atrial mass. When she presented with headaches and planned for a palliative craniotomy, a transthoracic echocardiography was performed as part of her pre-operative assessment. This examination showed a small LV chamber, an increase in the ventricular mass, and a

moderate pericardial effusion. A mass within the intra-atrial septum was noted but the ability to visualize the mass was noted to be technically limited. In light of these findings, a TEE was planned to assess the patient immediately after induction of anesthesia for the craniotomy.

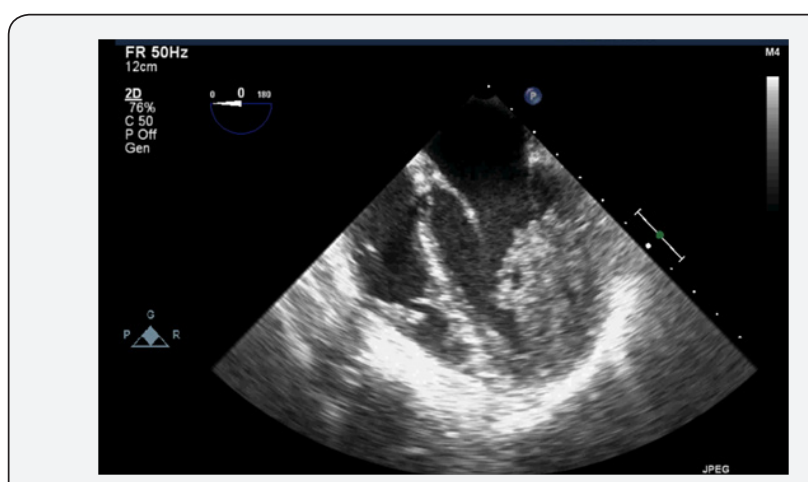

Figure 1: Transesophageal echocardiogram (TEE) 4 chamber view showing a mass attached to the lateral wall of left ventricle extending to the apex.

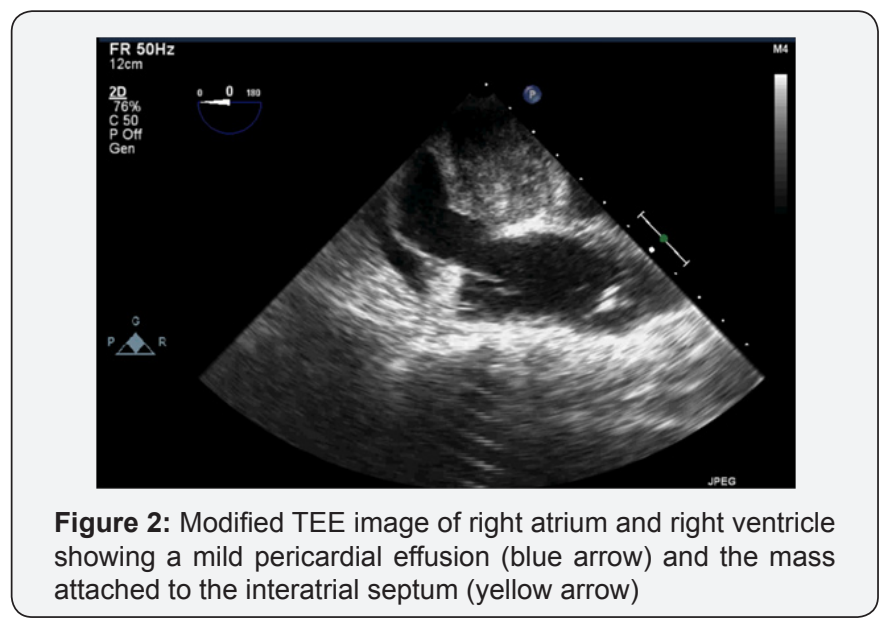

The TEE showed masses in the left ventricle, intra-atrial septum, and a small pericardial effusion. Figure 1 demonstrates a transesophageal echocardiography (TEE) in diastolic mid- 
esophageal apical four chamber view. It shows a large mass occupying majority of the left ventricular cavity that extends from the apex towards the base. Measuring $3.8 \mathrm{~cm}$ by $5.58 \mathrm{~cm}$, it remains attached to the lateral wall. The left ventricular wall motion is grossly normal. Figure 2 displays a modified TEE image of the right atrium and right ventricle. The second mass is attached from the mid to inferior portion of the interatrial septum involving the area of the fossa ovalis. The mass also protrudes into the right and left atrium. This view also shows a mild pericardial effusion around the right atrium. The mitral and tricuspid valves are grossly normal. Figure 3 shows a TEE transgastric short axis view. The mass, measuring $3.8 \mathrm{~cm}$ by $3.9 \mathrm{~cm}$ is attached to the lateral wall of the left ventricle. Surgical craniotomy proceeded uneventfully. The patient underwent re-staging of disease 2 weeks after her surgery and the CT scan showed masses in the left ventricle of 4.9 $\mathrm{x} 3.3 \mathrm{~cm}$, the intra-atrial septal mass had grown from $4 \times 3.1 \mathrm{~cm}$ to $5.3 \times 5.4 \mathrm{~cm}$. The right atrium showed a mass measuring $1.3 \times 0.9$ $\mathrm{cm}$. Two months after her craniotomy, the patient died in hospice care, presumably from a hemorrhagic lesion in the cerebellum for which she was not a surgical candidate.

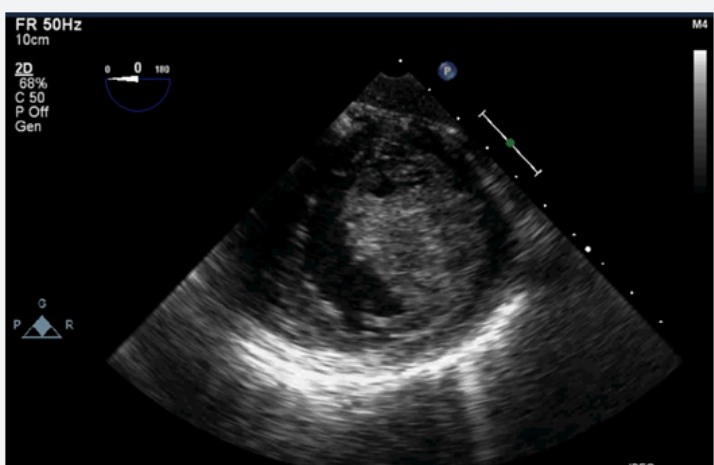

Figure 3: TEE Transgastric short axis view of left ventricle showing the mass attached to lateral wall of the left ventricle.

\section{Discussion}

Primary cardiac tumors are rare, but cardiac metastatic disease to the heart occurs in approximately $5 \%$ of patients with terminally ill cancer [2]. Melanoma, lung cancer, lymphoma, and breast cancers have the highest rates of cardiac metastasis. Cardiac involvement is present in approximately $64 \%$ of cases with metastatic melanoma $[3,4]$. The primary malignancy of our patient was a clear cell sarcoma, which is a rare, variant type of tumor that is often classified as a type of melanoma. Given the low incidence of clear cell sarcoma, prediction of cardiac metastasis is difficult. However given that clear cell sarcoma exhibits much of the same clinical behavior of metastatic melanoma, we chose to review melanoma in addition to these rare sarcomas, since clinicians should assess for cardiac disease in either diagnosis. Cardiac involvement of clear cell sarcoma was studied at the Osaka University Graduate School of Medicine in Japan. Their study looked at 641 patients with sarcoma and identified 11 patients who were diagnosed with intercardiac lesions while living, of these, 2 patients carried the diagnosis of clear cell sarcoma. The overall findings of their study recommended routine echocardiography to assess for cardiac lesions in any soft tissue sarcoma [5-8]. Malignant melanoma can appear at almost any anatomical location and with a relatively unpredictable time scale. Relative to the heart, one author indicated cardiac metastasis was observed upon autopsy in 45 out of 70 patients with malignant melanoma. Malignant melanoma most commonly involves the myocardium and a preference for the right atrium, although any location could potentially be involved [1]. One theory for melanomic cardiac affinity relates to a common embryonic neural crest origin [3]. The endocardial cushions, which are derived from neural crest, form part of cardiac septae. For patients with malignant melanoma and soft tissue sarcomas, clinicians should consider utilizing screening for assessing cardiac involvement using TTE or TEE, given the incidence of cardiac metastasis associated with disease progression.

\section{References}

1. Wood A, Markovic SN, Best PJ, Erickson LA (2010) Metastatic malignant melanoma manifesting as an intracardiac mass. Cardiovascular Pathology 19(3): 153-157.

2. Geller AC, Clapp RW, Sober AJ, Gonsalves L, Mueller L, et al. (2013) Melanoma Epidemic: An Analysis of Six Decades of Data from the Connecticut Tumor Registry. J Clin Oncol 31(33): 4172-4178.

3. Gul B, Young MN, Slosky DA, Lawson MA, Rottman JN (2014) An uncommon presentation for cardiac melanoma. J Patient-Centered Res Rev 1(2014): 128-32.

4. Erdei E, Torres SM (2010) A new understanding in the epidemiology of melanoma. Expert Review of Anticancer Therapy. 10(11): 1811-1823.

5. Takenaka S, Hashimoto N, Araki N, Hamada K, Naka N, et al. (2011) Eleven cases of cardiac metastases from soft-tissue sarcomas. Jpn J Clin Oncol 41(4): 514-518.

6. Onan B, Onan IS, Polat B (2010) Surgical resection of solitary metastasis of malignant melanoma to the right atrium. Tex Heart Inst J 37(5): 598-601.

7. Ozyuncu N, Sahin M, Altin T, Karaoguz R, Guldal M, et al. (2006) Cardiac metastasis of malignant melanoma: a rare cause of complete atrioventricular block. Europace 8(7): 545-548.

8. Ramchand J, Wong GR, Yudi MB, Sylivris S (2016) Cardiac metastatic melanoma. BMJ Case Reports. 
- Quality Editorial service

- Swift Peer Review

- Reprints availability

- E-prints Service

- Manuscript Podcast for convenient understanding

- Global attainment for your research

- Manuscript accessibility in different formats

( Pdf, E-pub, Full Text, Audio)

- Unceasing customer service

Track the below URL for one-step submission https://juniperpublishers.com/online-submission.php 